\title{
Stroke in Young Adults: Experience at Abakaliki South East Nigeria
}

\author{
Chukwuemeka O. Eze*, Uma A. Kalu, Godsent C. Isiguzo \\ Internal Medicine Department, Alex Ekwueme Federal University Teaching Hospital Abakaliki (AEFUTHA), Abakaliki, Nigeria \\ Email: *drezeconauth@yahoo.com, ^drezeconauth@gmail.com
}

How to cite this paper: Eze, C.O., Kalu, U.A. and Isiguzo, G.C. (2019) Stroke in Young Adults: Experience at Abakaliki South East Nigeria. World Journal of Neuroscience, 9, 217-223.

https://doi.org/10.4236/wjns.2019.94015

Received: August 18, 2019

Accepted: September 9, 2019

Published: September 12, 2019

Copyright (๑) 2019 by author(s) and Scientific Research Publishing Inc. This work is licensed under the Creative Commons Attribution International License (CC BY 4.0).

http://creativecommons.org/licenses/by/4.0/

\begin{abstract}
Objectives: Stroke is a major cause of morbidity and mortality worldwide. It is increasingly common from the sixth decade, but is particularly tragic when it occurs in young adults. There are limited studies of stroke in young adults in Nigeria. It is against this background that we embarked on this prospective hospital based study to determine the epidemiology, pattern and case fatality rate of stroke in young adults in Abakaliki Southeastern part of Nigeria. Patients and Method: The stroke patients between the ages of 18 - 50 years admitted to the medical wards of a tertiary health centre at Abakaliki Nigeria from 1st August 2012 to 30th April 2019 were consecutively recruited. They were followed up till discharge. Relevant data like biodata, and clinical features of the patients were extracted and analyzed. Results: A total of 983 (males-511, females-472) stroke cases were seen with 197 between 18 - 50 years. One hundred and fifty two (77\%) did neuroimaging (mean age-40.7 years). Eighty-eight (57.9\%) had Cerebral infarct (males-42, females-46) while $64(42.1 \%)$ had Hemorrhagic stroke (males-35, females-29). For those that had hemorrhagic stroke, 11 (17.2\%) were Subarachnoid hemorrhage (SAH) while $52(82.8 \%)$ were Intracerebral hemorrhage (ICH). The identified risk factors range from hypertension, DM, dyslipidemia, alcoholism, cigarette smoking, HIV infection and chronic use of coffee drinks. Sixteen patients died during the admission with case fatality rate of $10.5 \%$. Conclusion: Stroke is actually prevalent in young adults as 1 in every 5 stroke patients seen was a young adult. In addition to the traditional risk factors, HIV/AIDS and chronic use of coffee drinks were also noted as emerging risk factors. There is need for a continuous health education and strong campaign on primary stroke prevention. Also, there is need for training of more neurologists with interest in stroke management and establishing comprehensive stroke centers at national, regional and local levels in order to contend adequately with the rising burden of stoke in young adults.
\end{abstract}




\section{Keywords}

Stroke, Young Adults, Risk Factors, Case Fatality Rate

\section{Introduction}

Stroke is characterized as a neurological deficit attributed to an acute focal injury of the central nervous system (CNS) by a vascular cause, including cerebral infarction, intracerebral hemorrhage (ICH), and subarachnoid hemorrhage (SAH) [1]. It is a major cause of disability and death worldwide [1]. It affects both gender and it's increasingly common from the sixth decade, although young patients are not exempted [2]. People of African descent are more susceptible than their Caucasian counterparts [3]. Studies on Stroke in young adults have used varied aged ranges [4] [5] [6] but we used 18 to 50 years in this study. The proportion of first-ever stroke in young adults differs from country to country, ranging from $<5 \%$ to $20 \%$ of all strokes [7] [8] [9]. Eze et al. [10] reported that 19\% of all stroke cases occurred in young adults in southeastern Nigeria in 2013 while Sarfo et al. [11] reported $24.3 \%$ in a multicentre case-control study in Nigeria and Ghana 2018. Stroke in the young is particularly tragic because the patients are in their most productive years in life with many responsibilities and dependents especially in sub-Saharan Africa where extended family system is prevalent. This will create a long-term burden on the victims, their families, and the community at large [5]. There are limited studies of stroke in young adults in Nigeria especially in south eastern part despite the devastating effects of stroke in this age group. It is against this background that we embarked on this prospective hospital based study to determine the epidemiology, pattern and case fatality rate of stroke in young adults in Abakaliki Southeastern part of Nigeria.

\section{Materials and Methods}

This is a prospective longitudinal observational hospital based study where consecutive stroke patients admitted to the medical wards of the Alex Ekwueme Federal University Teaching Hospital Abakaliki (AEFUTHA) were recruited from 1st August 2012 to 30th April 2019. The patients were admitted from medical emergency room or medical outpatient clinics. The stroke patients between the ages of 18 and 50 years who had neuro-imaging (computed tomography/magnetic resonance imaging) confirmed stroke were included in the study. Relevant data like biodata, clinical features, risk factors and modified Rankin scale score (mRS) of the patients were extracted and analyzed at presentation. They were followed up to either discharge or death and their mRS was also noted. Hypertension was defined as admission systolic blood pressure of $\geq 140 \mathrm{mmHg}$ and/or diastolic blood pressure of $\geq 90 \mathrm{mmHg}$ or prior use of antihypertensive medications. Diabetes mellitus was defined as random blood glu- 
cose of $\geq 200 \mathrm{mg} / \mathrm{dl}$ or fasting blood glucose of $\geq 126 \mathrm{mg} / \mathrm{dl}$ and polyuria or prior use of anti diabetic medications. Dyslipidaemia is defined as serum Triglyceride $>150 \mathrm{mg} / \mathrm{dl}$, or High density lipoprotein $<40 \mathrm{mg} / \mathrm{dl}$ for males and $<50$ $\mathrm{mg} / \mathrm{dl}$ for females or prior specific treatment for dyslipidaemia. Obesity is defined as waist circumference of $\geq 94 \mathrm{~cm}$ in males and $\geq 80 \mathrm{~cm}$ in females. Alcohol abuse is defined as use $>21$ units/week for males and $>14$ units /week for females. The number of units of alcohol in a drink can be determined by multiplying the volume of the drink (in millilitres) by its percentage (Alcohol by volume), and dividing by 1000 [12]. Chronic excessive use of caffeinated drinks is defined as dependence (psychological or physiological) on caffeinated drinks with presence of $\geq 2$ caffeine withdrawal symptoms like headache, anxiety, poor concentration, tremors, and depression. The patients were also screened for Human immune deficiency virus (HIV). The data was analyzed using SPSS version 19. Chi square and Fisher exact test were used to test for statistical significance of categorical variables and student $t$-test for numerical variables. $p$ value of less than 0.05 is taken to be significant.

\section{Results}

During the study period from 1st August 2012 to 30th April 2019, a total of 983 (males-511, females-472) stroke cases were admitted to medical wards. Out of the 197 (20\% of total stroke patients) patients that were between 18 to 50 years, $152(77 \%)$ did brain neuro-imaging (Computed Tomography/magnetic resonance imaging scan) and were eligible for the study. The range was 26 - 49 years with mean age of $40.7 \pm 9.3$ years. The age distribution is shown in Table 1. Eighty-eight (57.9\%) had Cerebral infarct (males-42, females-46) while $64(42.1 \%)$ had Hemorrhagic stroke (males-35, females-29). For those that had hemorrhagic stroke, 11 (17.2\%) were Subarachnoid hemorrhage (SAH) (Male-32\%, Females-68\%) while 52 (82.8\%) were Intracerebral hemorrhage (ICH) (Males-61\%, Female-39\%). The identified risk factors range from hypertension, DM, dyslipidemia, obesity, alcohol abuse, smoking, HIV and chronic use of caffeinated drinks. The details are shown in Table 2. Admission mean modified Rankin scale (mRS) was 4.2 while the discharge mRS at discharge was 2.5 . The details are shown in Table 3 . Sixteen patients died during the admission with case fatality rate of $10.5 \%$. The details are shown in Table 4.

Table 1. Age distribution.

\begin{tabular}{cccc}
\hline Age range (years) & Male n (\%) & Female n (\%) & Total N (\%) \\
\hline$\leq 30$ & $7(4.6)$ & $1(0.7)$ & $8(5.3)$ \\
$31-40$ & $15(9.9)$ & $26(17.1)$ & $41(27.0)$ \\
$41-50$ & $58(38.2)$ & $45(29.6)$ & $103(67.8)$ \\
Total & $80(52.6)$ & $72(47.4)$ & $152(100.0)$ \\
\hline
\end{tabular}


Table 2. Identified risk factors.

\begin{tabular}{cccc}
\hline Risk factor & Cerebral infarct (\%) & Hemorrhagic stroke (\%) & p-value \\
\hline Hypertension & $50(56.8)$ & $52(81.3)$ & 0.0017 \\
Diabetes mellitus & $13(14.8)$ & $29(45.3)$ & $<0.05$ \\
Dyslipidemia & $11(12.5)$ & $17(26.6)$ & 0.0344 \\
Obesity & $12(13.6)$ & $15(23.4)$ & 0.1359 \\
Alcohol abuse & $14(15.9)$ & $2(3.1)$ & 0.0143 \\
Smoking & $12(13.6)$ & $1(1.6)$ & 0.008 \\
HIV/AIDS & $8(9.1)$ & $4(6.3)$ & 0.762 \\
Chronic use & $4(4.5)$ & $1(1.6)$ & 0.3982 \\
\hline
\end{tabular}

Table 3. Modified Rankin scale (mRS).

\begin{tabular}{ccc}
\hline mRS & Admission (\%) n-152 & Discharge (\%) n-152 \\
\hline $0-1$ & $11(7.2)$ & $50(32.9)$ \\
$2-3$ & $64(42.1)$ & $74(48.7)$ \\
$4-5$ & $77(50.7)$ & $12(7.9)$ \\
6 & $0(0.0)$ & $16(10.5)$ \\
\hline
\end{tabular}

Table 4. Stroke outcome.

\begin{tabular}{cccc}
\hline Outcome & $\begin{array}{c}\text { Cerebral infarct (\%) } \\
\text { n-88 }\end{array}$ & $\begin{array}{c}\text { Hemorrhagic stroke (\%) } \\
\text { n-64 }\end{array}$ & p-value \\
\hline Dead & $2(2.5)$ & $14(19.7)$ & 0.000043 \\
Survived & $86(97.5)$ & $50(80.3)$ & \\
\hline
\end{tabular}

\section{Discussion}

This is the first study on stroke in young adults in Abakaliki Southeastern Nigeria. During the study period, a total of 983 stroke cases were seen with 152 (15.5\%) occurred in young adults. This is in keeping with other studies that reported $>5 \%$ - 20\% [7] [8] [9] [10] though lower than 24.3\% reported by Sarfo et al. [11]. This difference could result from exclusion of stroke patients who did not do neuroimaging from this study. When the stroke patients that did not do neuroimaging are included in the analysis, it will come up to $20 \%$. This suggests that stroke is actually prevalent in young adults as against the notion that it is disease of the elderly. The morbidity of stroke in this age group is far reaching as they are in their most productive years of life. This contributes to huge disability adjustable life years (DALYs).

The sex distribution of males-80 (52.6\%) and females-72 (47.4\%) with sex ratio was about 1:1 is similar to the report of Onwuchekwa et al. in South-south Nigeria [13]. Owolabi et al. reported a higher prevalence in young males than female folks in Northwestern Nigeria [5]. This finding could suggest that the 
prevalence of stroke may actually be in the rise amongst young female folks. It could also be a false picture in support of the report that women have better health seeking behavior in Nigeria and are more likely to come to the hospital when ill than their male counterparts [14].

The age distribution revealed an increase in stroke prevalence with increase in age as $68 \%$ of the patients were between age range of $41-50$ years. This is similar to other hospital based studies in Nigeria [5] [15]. This is not surprising as increasing age is an established risk factor for stroke. Also the prevalence of other stroke risk factors increases with age.

Cerebral infarct was $57.9 \%$ while hemorrhagic stroke was $42.1 \%$ in this study. This is similar to the $59 \%$ for cerebral infarct and $41 \%$ for hemorrhagic stroke reported by Owolabi et al. [5] but in variance with Oyinloye et al. [15] who reported $48.3 \%$ for cerebral infarct and $51.7 \%$ for hemorrhagic stroke and Sarfo et al. [11] who reported $47.5 \%$ and $52.5 \%$ for ischemic and Hemorrhagic strokes respectively. The variance could stern from the fact that Oyinloye et al. [15] reported neuroimaging results at a neuroimaging centre which could be biased as hemorrhagic strokes, which is usually more severe are more likely to do neuroimaging than the ischemic counterpart. Sarfo et al. [11] did a multicentre study in Ghana and Nigeria with larger sample size which excluded southeastern Nigeria where this study was carried out. There may be variance in local health determinants which include feeding pattern, health seeking behaviors and cultural practices that could have affected the findings.

For those that had hemorrhagic stroke, $17.2 \%$ were subarachnoid hemorrhage (SAH) while $82.8 \%$ had intracerebral hemorrhage. This is similar to $32 \%$ and $68 \%$ reported by Oyinloye et al. [15] Subarachnoid hemorrhage is assuming a big role in the morbidity and mortality of stroke in Nigeria considering its poor prognosis. SAH was more preponderant amongst female patients as $68 \%$ were female. This is expected as berry aneurysm, which is the most common risk factor for SAH is more prevalent in women [16].

The identified risk factors were hypertension, Diabetes mellitus, dyslipidemia, obesity, alcohol abuse, smoking, HIV/AIDS and chronic use of coffee drinks in descending order of frequency. This is similar to the findings of other hospital based studies in Nigeria [5] [15] [17] except that none of them reported chronic use of coffee drinks. The chronic use of coffee drinks was noted more in cerebral infarct. This association is not unexpected as caffeine is known to induce endothelial cell dysfunction which is a harbinger for atherosclerosis and cerebral infarct [18].

About $80 \%$ of the patients made significant recovery at discharge (mRS-0 3 ), with a case fatality rate of $10.5 \%$ which is lower than $23.9 \%$ reported by Owolabi et al. and 29.6\% reported by Onwuchekwa et al. [5] [13].

The lower case fatality rate in this study could stern from the fact that most of the patients were managed in a Neurology unit with interest in stroke. Exclusion of fatality at medical emergency room in this study could also have led to lower case fatality rate recorded. 
Eighty-eight per cent of the mortality had hemorrhagic stroke. This is expected as hemorrhagic stroke is known to have a worse prognosis than cerebral infarct [19].

\section{Conclusions and Recommendations}

This study revealed that stroke is actually prevalent in young adults as 1 in every 5 stroke patients seen was a young adult. There was almost equal sex distribution with majority of the cases in their fifth decade of life. Cerebral infarct was more prevalent with almost equal sex distribution while $\mathrm{ICH}$ and $\mathrm{SAH}$ were more preponderant amongst the male and female folks respectively. In addition to the traditional risk factors, HIV/AIDS and chronic use of coffee drinks were also noted as emerging risk factors. The case fatality rate was relatively low.

There is need for continuous health education and strong campaign on primary stroke prevention. Also, there is need for training of more neurologists with interest in stroke management and establishing comprehensive stroke centers at national, regional and local levels in order to contend adequately with the rising burden of stoke in young adults.

\section{Limitations}

The exclusion of the stroke patients that died at emergency room could have affected the case mortality rate.

\section{Conflicts of Interest}

The authors declare no conflicts of interest regarding the publication of this paper.

\section{References}

[1] Sacco, R.L., Kasner, S.E., Broderick, J.P., Caplan, L.R., Culebras, A., Elkind, M.S., George, M.G., et al. (2013) An Updated Definition of Stroke for the 21st Century. Stroke, 44, 2064-2089. https://doi.org/10.1161/STR.0b013e318296aeca

[2] Schulte, B.P. (1989) Neuroepidemiology of Cerebrovascular Disease: An Overview in Advances in Neurology. Proceedings of the 14th World Congress of Neurology, New Delhi, 3.

[3] Agyemang, C., Addo, J., Bhopal, R., Aikins Ade, G. and Stronks, K. (2009) Cardiovascular Disease, Diabetes and Established Risk Factors among Populations of Sub-Saharan African Descent in Europe: A Literature Review. Global Health, 5, 7. https://doi.org/10.1186/1744-8603-5-7

[4] Martin, P.J., Enevoldson, T.P. and Humphrey, P.R. (1997) Causes of Ischaemic Stroke in the Young. Postgraduate Medical Journal, 73, 8-16. https://doi.org/10.1136/pgmj.73.855.8

[5] Owolabi, L.F. and Ibrahim, A. (2012) Stroke in Young Adults: A Prospective Study from Northwestern Nigeria. ISRN Neurology, 2012, Article ID: 468706. https://doi.org/10.5402/2012/468706

[6] Băsić Kes, V., Zavoreo, I. and Demarin, V. (2012) Etiology and Diagnostic Work-Up in Young Stroke Patients. Periodicum Biologorum, 114, 355-359. 
[7] Nedeltchev, K., der Maur, T.A. and Georgiadis, D. (2005) Ischaemic Stroke in Young Adults: Predictors of Outcome and Recurrence. Journal of Neurology, Neurosurgery, and Psychiatry, 76, 191-195. https://doi.org/10.1136/jnnp.2004.040543

[8] Varona, J.F., Guerra, J.M., Bermejo, F., Molina, J.A. and de la Camara, G. (2007) Causes of Ischemic Stroke in Young Adults, and Evolution of the Etiological Diagnosis over the Long Term. European Neurology, 57, 212-218.

https://doi.org/10.1159/000099161

[9] George, M.G., Tong, X., Kuklina, E.V. and Labarthe, D.R. (2011) Trends in Stroke Hospitalizations and Associated Risk Factors among Children and Young Adults, 1995-2008. Annals of Neurology, 70, 713-721. https://doi.org/10.1002/ana.22539

[10] Eze, C.O., Agu, C.E., Kalu, U.A., Maduanusi, C.A., Nwali, S.T. and Igwenyi, C. (2013) The Pattern and Presentation of Stroke in Federal Teaching Hospital Abakaliki (FETHA) South-East Nigeria. Journal of Biology, Agriculture and Healthcare, 3, 141.

[11] Sarfo, F.S., Ovbiagele, B., Gebregziabher, M., Wahab, K., Akinyemi, R., Akpalu, A., Akpa, O., Obiako, R., Owolabi, L., Jenkins, C. and Owolabi, M. (2018) Stroke among Young West Africans: Evidence from the SIREN (Stroke Investigative Research and Educational Network) Large Multisite Case-Control Study. Stroke, 49, 1116-1122. https://doi.org/10.1161/STROKEAHA.118.020783

[12] How Long Does Alcohol Stay in Your Blood? NHS Choices.

[13] Onwuchekwa, A.C., Onwuchekwa, R.C. and Asekomeh, E.G. (2009) Stroke in Young Nigerian Adults. Journal of Vascular Nursing, 27, 98-102. https://doi.org/10.1016/j.jvn.2009.08.001

[14] Odaman, O.M. and Ibiezugbe, M.I. (2014) Health Seeking Behavior among the Elderly in Edo Central Nigeria. International Review of Social Sciences and Humanities, 7, 201-210.

[15] Oyinloye, O., Nzeh, D., Adesiyun, O., Ibrahim, M., Akande, H. and Sanya, E. (2015) Neuroimaging of Young Adults with Stroke in Ilorin Nigeria. Annals of African Medicine, 14, 82-88. https://doi.org/10.4103/1596-3519.149897

[16] Rinkel, G.J., Djibuti, M., Algra, A. and Gijn, J. (1998) Prevalence and Risk of Rupture of Intracranial Aneurysms-A Systematic Review. Stroke, 29, 251-256. https://doi.org/10.1161/01.STR.29.1.251

[17] Nwosu, C.M., Nwabueze, A.C. and Ikeh, V.O. (1992) Stroke at the Prime of Life: A Study of Nigerian Africans between the Ages of 16 and 45 Years. East African Medical Journal, 69, 384-390.

[18] Planning Committee for a Workshop on Potential Health Hazards Associated with Consumption of Caffeine in Food and Dietary Supplements, Food and Nutrition Board; Board on Health Sciences Policy, Institute of Medicine (2014) Caffeine in Food and Dietary Supplements: Examining Safety. National Academies Press, Washington DC.

[19] Eze, C.O. and Kalu, U.A. (2014) The Prognosis of Acute Stroke in a Tertiary Health Centre in South-East Nigeria. Nigerian Journal of Medicine, 23, 306-310. 